\title{
Controle químico do cancro cítrico em plantas jovens sob manejo convencional e orgânico
}

\author{
Quemical control of citrus canker in young plants managed in conventional and organic systems
}

\author{
Otto Carlos Koller ${ }^{1}$ Regina Beatriz Loss de Oliveira ${ }^{2}$ Diego Soares Nunes ${ }^{3}$ Fábio Dal Soglio $^{4}$ \\ Nestor Valtir Panzenhagen² ${ }^{2}$ var Antônio Sartori² ${ }^{2}$ Francisco Manteze ${ }^{5}$
}

RESUMO

O objetivo deste trabalho foi avaliar o desenvolvimento de porta-enxertos de Poncirus trifoliata Raf. e de enxertos de laranjeira "Valência" (Citrus sinensis Osb.), os índices de ataque de cancro cítrico, causado pela bactéria Xanthomonas citri pv. citri, artificialmente inoculada, e o controle dessa moléstia, com pulverizações cúpricas em sistemas de cultivo, convencional e orgânico, no Centro de Formação da EMATER, situado no município de Montenegro, Estado do Rio Grande do Sul. Foram testadas pulverizações cúpricas a cada 7, 14 e 21 dias, com concentrações de 0,15 e $0,30 \%$ de cobre metálico, utilizando calda bordalesa no sistema orgânico e oxicloreto de cobre no sistema convencional. Foram avaliados o crescimento do diâmetro do caule das plantas, a produção de matéria seca da parte aérea dos porta-enxertos, o número de folhas com lesões de cancro cítrico e o número de lesões presentes por folha atacada. Verificou-se que em ambos os sistemas de cultivo, no convencional e no orgânico, o desenvolvimento dos porta-enxertos foi semelhante, mas os enxertos cresceram mais no sistema convencional. Com elevada presença de fontes de inóculo, os tratamentos cúpricos não controlaram o cancro cítrico nos porta-enxertos. Já nos enxertos, com baixa presença de fontes de inóculo, tanto a calda bordalesa como o oxicloreto de cobre controlaram a doença, com melhor resposta na concentração de 0,3\% de cobre metálico, aplicada em intervalos de 14 dias. Para melhorar o controle do cancro cítrico, com calda bordalesa, em sistemas orgânicos de cultivo, devem ser desenvolvidas medidas eficazes de controle da larva-minadora.

Palavras-chave: citros, manejo, controle de doença, cultivo orgânico, cultivo convencional, Xanthomonas citri pv. citri.

\begin{abstract}
The objective of the present work was to evaluate the development of the citrus rootstock Poncirus trifoliata, severity of citrus canker, caused by Xanthomonas citri pv. citri and the control of this disease with copper sprays, in conventional and organic management systems, at the Centro de Formação da EMATER, located in Montenegro, Rio Grande do Sul. Plants were artificially inoculated with the bacteria. To control citrus canker, different sources of copper as well as concentrations and number of sprays were tested. In the organic system the bordeaux mixture was applied while in the conventional system copper oxichloride was sprayed. Plants trunk diameter, dry matter of the rootstocks and number of canker lesions on leaves and branches were evaluated in both systems. Citrus canker incidence on the rootstocks was equally intense, and the seedlings development was similar in both systems, but the budded plants grew better at the conventional system. Copper treatments were not effective in controlling citrus canker at the rootstocks due the high inoculum concentration. On the budded plants, with low inoculum concentration, both the Bordeaux mixture and the copper oxichloride controlled the disease, and the better treatments were when $0.3 \%$ metallic copper was applied with interval of 14 days. To improve citrus canker control by Bordeaux mixture on organic systems, there is a need of efficient control strategies of the citrus leaf miner.
\end{abstract}

Key words: citrus canker, organic management, conventional management, rootstock, Xanthomonas citri pv. citri.

\footnotetext{
${ }^{1}$ Departamento de Horticultura e Silvicultura da Faculdade de Agronomia da Universidade Federal do Rio Grande do Sul (UFRGS). Av. Bento Gonçalves 7712, Bairro Agronomia, 91501-970, Porto Alegre, RS, Brasil. E-mail: ockoller@adufrgs.ufrgs.br. ${ }^{2}$ Programa de Pós-graduação em Fitotecnia, UFRGS, Porto Alegre, RS, Brasil.

${ }^{3}$ Curso de Agronomia da Faculdade de Agronomia, UFRGS, Porto Alegre, RS, Brasil.

${ }^{4}$ Departamento de Fitossanidade da Faculdade de Agronomia, UFRGS, Porto Alegre, RS, Brasil.

${ }^{5}$ Emater/RS, Centro de Formação da Emater/RS, Montenegro, RS, Brasil.
} 


\section{INTRODUÇÃO}

No Brasil, maior produtor mundial de citros, com uma produção de 20.526.500 toneladas de frutas (FAO, 2005), a citricultura é uma das mais importantes atividades agrícolas. No Estado do Rio Grande do Sul, que ocupa a $5^{\mathrm{a}}$ posição entre os maiores produtores de citros do país, com produção aproximada de 450.000 toneladas (IBGE 2005), a citricultura também é uma atividade de destaque. Contudo, o cancro cítrico, moléstia causada pela bactéria Xanthomonas citri pv. citri, é considerado uma ameaça potencialmente grave para diversas regiões produtoras de citros do Brasil (LEITE JÚNIOR et al., 1988), pois trata-se de uma doença séria, que ataca a maioria das cultivares comerciais.

Assim sendo, a legislação vigente prevê a proibição da comercialização de frutas e mudas contaminadas, bem como a erradicação de viveiros e pomares afetados. Porém, em grandes áreas da Região Sul do Brasil, onde a agricultura familiar é praticada e nas quais os pomares de citros raramente são superiores a 3 hectares, sendo a principal fonte de sustento dessas famílias, a execução da legislação é difícil, pois não está prevista nenhuma forma de indenização ao agricultor, nem incentivos para o estabelecimento de culturas alternativas, o que geraria muitos problemas.

Algumas pesquisas já evidenciaram que pulverizações com bactericidas cúpricos reduzem o desenvolvimento do cancro cítrico (LEITE JUNIOR et al., 1987). Segundo MACIEL (1994), diversos trabalhos já foram realizados visando a avaliar a real capacidade dos cúpricos no sentido de controlar o cancro cítrico, concluindo-se que a eficiência desses produtos tem apenas ação de proteção dos tecidos suscetíveis à penetração da bactéria. Tem-se observado também que as pulverizações são mais eficazes no controle do cancro cítrico se outras práticas culturais concomitantes forem adotadas, como proteção contra ventos fortes e a poda de tecidos lesionados, para diminuir as fontes de inóculo (CANTEROS, 2005).

Pesquisas em pomares são onerosas e de difícil execução (THEISEN, 2004). Assim sendo, optouse pela utilização de porta-enxertos, artificialmente inoculados com a bactéria, e mudas enxertadas distribuídas em pequenas áreas e submetidas a dois sistemas de manejo: convencional e orgânico. O trabalho objetivou estudar o controle do cancro cítrico sob duas condições: manejo convencional e manejo orgânico.

\section{MATERIAL E MÉTODOS}

O experimento foi realizado numa área isolada do Centro de Formação da Emater/RS, localizado no município de Montenegro/RS, onde, em julho do ano 2000, foram plantados porta-enxertos de Poncirus trifoliata Raf., em espaçamento de $0,20 \mathrm{~m}$ na linha e de $1 \mathrm{~m}$ entre linhas, sob dois sistemas de cultivo: um deles com manejo convencional, compreendendo o emprego de herbicidas, fertilizantes e defensivos químicos, e o outro com manejo orgânico.

Em épocas de intensa brotação dos portaenxertos, estes foram uniformemente inoculados com três pulverização consecutivas de uma suspensão contendo 108ufc $\mathrm{ml}^{-1}$ de bactérias de Xanthomonas citri pv. citri (MAVRODIEVA et al., 2004). Em abril de 2001, realizou-se a enxertia com borbulhas de laranjeira "Valência” [Citrus sinensis (L.) Osb].

Para o controle do cancro cítrico no sistema de cultivo convencional, foram testadas pulverizações com oxicloreto de cobre e, no sistema orgânico, com calda bordalesa, nas seguintes concentrações de cobre metálico e freqüências de aplicação: A) testemunha, sem pulverizações; B) 0,15\% de cobre metálico a cada 7 dias; C) $0,15 \%$ a cada 14 dias; D) $0,15 \%$ a cada 21 dias; E) 0,30\% a cada 7 dias; F) 0,30\% a cada 14 dias; G) $0,30 \%$ a cada 21 dias.

O delineamento experimental foi blocos ao acaso, com sete tratamentos e cinco repetições. Na fase de porta-enxertos, cada parcela experimental foi formada por 16 plantas dispostas em linha, sendo úteis as 10 plantas centrais, e, na fase de mudas enxertadas, foram consideradas úteis só seis plantas centrais. Foi deixada uma linha de plantas como bordadura separando os blocos. As pulverizações com produtos cúpricos só foram iniciadas 32 dias após o surgimento dos sintomas de cancro, resultantes da inoculação nos porta-enxertos. Ao redor de ambas as áreas foi plantada uma linha de capim Cameroon (Pennissetum purpureum) para protegê-las de ventos fortes.

No sistema convencional, em pré-plantio, com base em análise química, foram incorporados ao solo $60 \mathrm{~kg} \mathrm{ha}^{-1}$ de $\mathrm{P}_{2} \mathrm{O}_{5}$ na forma de fosfato natural e $100 \mathrm{kgha}^{-1}$ de $\mathrm{K}_{2} \mathrm{O}$ na forma de cloreto de potássio e calagem com $5 \mathrm{t} \mathrm{ha}{ }^{-1}$ de calcário dolomítico, visando a elevar o pH a 6,0. No sistema orgânico, foi feita aplicação pré-plantio de $300 \mathrm{~m}^{3} \mathrm{ha}^{-1}$ de composto orgânico e $70 \mathrm{~m}^{3} \mathrm{ha}^{-1}$ de biofertilizante líquido. Posteriormente, em cobertura, no sistema convencional, foram realizadas três adubações nos porta-enxertos e três nos enxertos com intervalos de três meses, cada uma com $200 \mathrm{~kg} \mathrm{ha}^{-1}$ de nitrato de potássio (32-00-02); no sistema orgânico, foi feita uma 
só aplicação de $300 \mathrm{~m}^{3}$ ha-1 de composto, espalhado em cobertura entre as linhas dos porta-enxertos, em outubro de 2000 .

No sistema convencional, a vegetação espontânea foi controlada com duas aplicações anuais de herbicida glyphosate, e a larva minadora (Phyllocnistis citrella Stainton) foi controlada através de pulverizações quinzenais, na fase vegetativa, com abamectin ( $0,03 \%$ de Vertimec) + 0,25\% de óleo mineral emulsionável. No sistema orgânico, foram realizadas 3 capinas manuais e pulverizações com 0,10\% de Dipel (Bacillus thurringensis) para controlar a larva minadora.

Para avaliar o crescimento vegetativo das mudas, foram realizadas medições do diâmetro do caule dos porta-enxertos e dos enxertos. Para acompanhar a evolução e/ou incidência de cancro cítrico, realizaramse três avaliações durante o cultivo dos porta-enxertos e três durante o crescimento dos enxertos. Em cada avaliação nos porta-enxertos, todos os ramos e folhas das plantas que apresentavam lesões foram podados e acondicionados em sacos plásticos. Nos enxertos, foram coletadas somente as folhas que tinham lesões. Em laboratório, contou-se o número de lesões de cada folha e pesou-se a matéria verde e seca do material podado.

Em agosto, realizou-se o decepamento dos porta-enxertos $1 \mathrm{~cm}$ acima da borbulha enxertada. Todo o material vegetal podado foi queimado após a avaliação.

Para a análise da variância, os dados obtidos em cada sistema de cultivo, em separado, foram transformados em $(x+1)^{1 / 2}$ e as médias foram comparadas pelo teste de Duncan a $5 \%$ de probabilidade de erro.

\section{RESULTADOS E DISCUSSÃO}

Com relação ao crescimento dos portaenxertos (Tabela 1), pode-se observar que, em ambos os viveiros, o desenvolvimento das plantas foi muito semelhante.

Com relação ao efeito dos tratamentos cúpricos, na medição final, a única diferença significativa entre tratamentos ocorreu no viveiro orgânico, no qual o menor crescimento das plantas aconteceu no tratamento $\mathrm{F}$, pulverização com 1,0\% de calda bordalesa a cada 14 dias. Isso, entretanto, não pode ser atribuído a efeito depressivo ou fitotóxico do cobre, pois, se assim o fosse, o caule dos porta-enxertos não teria atingido o maior diâmetro no tratamento E, pulverização com 1,0\% de calda bordalesa a cada sete dias, visto que, neste tratamento, as plantas receberam o dobro do cobre do tratamento F. O fato de não ter havido diferenças significativas posteriormente entre os tratamentos para o diâmetro do caule dos enxertos ou para a testemunha também atesta que as pulverizações cúpricas não prejudicaram o crescimento das plantas.

As lesões de cancro cítrico presentes na primeira avaliação (Tabela 2), que foram registradas 38 dias após terem sido detectadas as primeiras lesões da doença, apenas revelam os índices de ataque de cancro cítrico que resultaram das inoculações artificiais, sem interferência das pulverizações cúpricas, que só foram feitas a partir de então.

Nesta primeira avaliação, as diferenças de ataque do cancro cítrico entre os dois viveiros não foram acentuadas. Entretanto, na maioria das variáveis avaliadas, quais sejam, número total de folhas com

Tabela 1 - Crescimento, em diâmetro do caule, de porta-enxertos de Poncirus trifoliata Raf. inoculados com Xanthomonas citri pv. citri e de enxertos de laranjeira "Valência” pulverizados com três freqüências e duas concentrações de bactericidas cúpricos, em dois sistemas de cultivo (orgânico e convencional). Centro de Formação da Emater/RS, no município de Montenegro/RS, 2003.

\begin{tabular}{|c|c|c|c|c|}
\hline \multirow{3}{*}{ Tratamentos } & \multicolumn{4}{|c|}{ Diâmetro do caule (mm) } \\
\hline & \multicolumn{2}{|c|}{ Porta-enxertos (junho 2002) } & \multicolumn{2}{|c|}{ Enxertos (maio de 2003) } \\
\hline & Sistema orgânico & Sistema convencional & Sistema orgânico & Sistema convencional \\
\hline Testemunha, sem pulveriz. cúprica & $9,9 a b^{1}$ & 9,3a & $8,8 a$ & $9,3 a$ \\
\hline 0,15 \% de Cu metálico a cada 7 dias & $10,1 \mathrm{ab}$ & $10,1 \mathrm{a}$ & $8,8 a$ & $9,5 a$ \\
\hline 0,15 \% de Cu metálico a cada 14 dias & $10,0 \mathrm{ab}$ & $10,1 \mathrm{a}$ & $8,6 a$ & $9,1 \mathrm{a}$ \\
\hline 0,15 \% de Cu metálico a cada 21 dias & $10,0 \mathrm{ab}$ & $9,7 a$ & $8,3 a$ & $9,4 a$ \\
\hline 0,30 \% de Cu metálico a cada 7 dias & $10,6 a$ & $10,5 a$ & 8,3a & $10,1 \mathrm{a}$ \\
\hline 0,30 \% de Cu metálico a cada 14 dias & $9,5 \mathrm{~b}$ & $10,2 \mathrm{a}$ & $8,6 a$ & $9,7 a$ \\
\hline 0,30 \% de Cu metálico a cada 21 dias & $10,4 \mathrm{a}$ & $10,0 \mathrm{a}$ & $8,8 \mathrm{a}$ & $10,0 \mathrm{a}$ \\
\hline Médias dos tratamentos & 10,1 & 10,0 & 8,6 & 9,6 \\
\hline
\end{tabular}

${ }^{1}$ Médias seguidas por letras distintas na coluna diferem entre si pelo teste de Duncan ao nível de significância de 0,05. 
Tabela 2 - Índices de ataque de cancro cítrico (Xanthomonas citri pv. Citri) em porta-enxerto de Poncirus trifoliata obtidos na primeira avaliação, 38 dias após a detecção das primeiras lesões, em dois sistemas de cultivo (orgânico e convencional). Centro de Formação da Emater/RS, em Montenegro/RS.

\begin{tabular}{|c|c|c|c|c|c|}
\hline Sistemas de cultivo & $\begin{array}{l}\text { Número de folhas } \\
\text { com lesões por } \\
\text { planta }\end{array}$ & $\begin{array}{l}\text { Número de } \\
\text { lesões/folha }\end{array}$ & $\begin{array}{l}\text { Total de lesões nas } \\
\text { folhas de cada planta }\end{array}$ & $\begin{array}{l}\text { Número de ramos } \\
\text { com lesões }\end{array}$ & $\begin{array}{c}\text { Matéria seca podada, } \\
\text { com lesões (g) }\end{array}$ \\
\hline Orgânico & $25 a^{1}$ & $6,0 \mathrm{a}$ & $149 a$ & $11 \mathrm{a}$ & $2,67 a$ \\
\hline Convencional & $32 \mathrm{a}$ & $4,9 a$ & $156 a$ & $15 a$ & $4,34 a$ \\
\hline
\end{tabular}

${ }^{1}$ Médias seguidas por letras distintas na coluna diferem entre si pelo teste de Duncan ao nível de significância de 0,05.

lesões/planta, número total de lesões nas folhas/planta, número de lesões nos ramos, e matéria seca podada, os valores apresentaram-se mais altos no viveiro convencional que no viveiro orgânico. Tal resposta indica que no viveiro convencional as plantas tendem a ser mais suscetíveis à inoculação artificial que no viveiro orgânico. Isso pode ter ocorrido em função das três adubações químicas de cobertura, com nitrato de potássio (32-0-2), cujo nitrogênio deve ter provocado forte brotação dos porta-enxertos, favorecendo a colonização pela bactéria. Já no viveiro orgânico a liberação de $\mathrm{N}$ pelo composto deve ter sido lenta. Essa dedução também encontra apoio no fato de a matéria seca do material contaminado e podado na primeira avaliação ter sido menor no viveiro orgânico.

Os índices de ataque de cancro cítrico nos porta-enxertos, apresentados na tabela 3, permitem observar que nos dos dois sistemas de cultivo não houve diferenças significativas nem entre os tratamentos cúpricos, nem entre estes e a testemunha, tanto para o número de folhas com lesões como para o número de lesões por folha. A ineficácia das pulverizações cúpricas é de certa forma estranha, visto que diversos pesquisadores, como LEITE JÚNIOR et al. (1987), LEITE JÚNIOR (1997) e CANTEROS (2005), afirmam que pulverizações cúpricas diminuem o ataque de cancro cítrico. Entretanto, em ambos os viveiros, quando foram iniciadas as pulverizações cúpricas, muitas folhas e ramos novos já podiam estar infectados sem que as lesões tivessem sido evidenciadas na primeira avaliação, pois, segundo CABRITA et al. (1981), dependendo de condições de temperatura e umidade, as lesões só se tornam visíveis a olho nu algumas semanas após a penetração das bactérias. Em condições ótimas, as lesões se evidenciam em 7 dias, segundo GOTTWALD et al. (2002); mas, segundo AMORIN et al. (2001), só após 10 a 14 dias. Assim, um grande número de folhas ou ramos já infectados provavelmente não foram podados na primeira época. Por conseguinte, na segunda avaliação, realizada apenas 32 dias após terem sido iniciadas as pulverizações cúpricas, foi detectado um grande número de lesões que se originaram antes da aplicação dos tratamentos e que não poderiam ter sido evitadas

Tabela 3 - Índices de ataque de cancro cítrico em folhas, em porta-enxertos de Poncirus trifoliata Raf., após inoculação com Xanthomonas citri pv. Citri, 32 dias após o início de pulverizações com duas concentrações de bactericidas cúpricos e três freqüências, em dois sistemas de cultivo (orgânico e convencional). Centro de Formação da EMATER/RS, no Município de Montenegro - RS, 2003.

\begin{tabular}{|c|c|c|c|c|}
\hline \multirow[b]{2}{*}{ Tratamentos } & \multicolumn{2}{|c|}{ Sistema orgânico } & \multicolumn{2}{|c|}{ Sistema convencional } \\
\hline & $\begin{array}{l}\mathrm{N}^{\mathrm{o}} \text { de folhas com } \\
\text { lesões por planta }\end{array}$ & $\begin{array}{l}\text { Número de lesões por } \\
\text { folha }\end{array}$ & $\begin{array}{l}\mathrm{N}^{\mathrm{o}} \text { de folhas com } \\
\text { lesões/planta }\end{array}$ & $\begin{array}{l}\text { Número de lesões por } \\
\text { folha }\end{array}$ \\
\hline Testemunha, sem pulveriz. cúprica & $54,2 \mathrm{a}$ & $5.7 \mathrm{a}$ & $26,3 a$ & 3,3a \\
\hline 0,15 \% de Cu metálico a cada 7 dias & $52,0 \mathrm{a}$ & $4,2 \mathrm{a}$ & $32,7 \mathrm{a}$ & $2,9 a$ \\
\hline 0,15 \% de Cu metálico a cada 14 dias & $37,8 a$ & $4,01 \mathrm{a}$ & $37,0 \mathrm{a}$ & $3,1 \mathrm{a}$ \\
\hline 0,15 \% de Cu metálico a cada 21 dias & $49,6 a$ & $5,9 a$ & 33,3а & $3,0 \mathrm{a}$ \\
\hline 0,30 \% de Cu metálico a cada 7 dias & $50,6 a$ & $4,0 \mathrm{a}$ & 29,1a & $2,3 a$ \\
\hline 0,30 \% de Cu metálico a cada 14 dias & $55,3 a$ & $5,6 a$ & 34,7 & $2.9 a$ \\
\hline 0,30 \% de Cu metálico a cada 21 dias & $54,0 \mathrm{a}$ & $4,4 a$ & $34,7 \mathrm{a}$ & $3,4 a$ \\
\hline Médias dos tratamentos & $50,50 a$ & $4,98 \mathrm{a}$ & $32,50 \mathrm{a}$ & $3,04 \mathrm{a}$ \\
\hline
\end{tabular}

${ }^{1}$ Médias seguidas por letras distintas na coluna diferem entre si pelo teste de Duncan ao nível de significância de 0,05.

Ciência Rural, v.36, n.4, jul-ago, 2006. 
na primeira pulverização, porque as bactérias já teriam penetrado nos tecidos.

Outra possibilidade da ausência de efeitos significativos das pulverizações cúpricas pode estar relacionada à intensa e freqüente brotação das plantas novas em solo abundantemente adubado, tornando constante a presença de tecidos suscetíveis à penetração das bactérias causadoras do cancro cítrico. Isto encontra amparo em observações feitas por LEITE JÚNIOR et al. (1987), que mostraram que a proteção dos tratamentos cúpricos contra o cancro cítrico é quase duas vezes menor em variedades de citros suscetíveis do que nas mais resistentes.

Por outro lado, o alto índice de ataque, resultante da forte inoculação e da demasiada demora na adoção de medidas de controle, podas e pulverizações cúpricas, permitiu que o potencial de inóculo se elevasse a um nível muito alto, tornando insignificante a proteção exercida pelas pulverizações cúpricas, cuja ação é mais efetiva em nível baixo de presença de inóculos (CANTEROS, 2005).

Quanto ao desenvolvimento de lesões de cancro cítrico nos enxertos, depois que foi removido e destruído todo o material contaminado dos portaenxertos, verificou-se (Tabela 4) que, em ambos os sistemas de cultivo, somente a partir da vistoria feita em março de 2003, foram constatadas folhas com lesões da doença. Nesta ocasião, também foi mais elevada a presença de sintomas, os quais decaíram na inspeção feita em maio de 2003.

A ausência de lesões até o mês de novembro atestou a eficiência da poda e da destruição das fontes de inóculos, como folhas, ramos e frutos com lesões, no controle do cancro cítrico, conforme foi demonstrado por LEITE JÚNIOR et al., 1987; THEISEN,
2004; CANTEROS, 2005. A elevada presença de lesões no mês de março deve ter decorrido de infecções verificadas nos meses de dezembro, janeiro e fevereiro, período de temperatura elevada e freqüentes chuvas.

Pode-se verificar também na tabela 4 que tanto a maior concentração como a maior freqüência de pulverizações cúpricas, em ambos os sistemas, diminuíram a presença de lesões nas folhas dos enxertos, sendo que se consegue o mesmo efeito de controle fazendo pulverizações a cada sete dias com concentrações de $0,15 \%$ de cobre metálico, ou só a cada 14 dias com $0,30 \%$ de cobre metálico. Assim, sendo igual o consumo de produtos cúpricos, é mais conveniente diminuir o trabalho, usando a concentração de $0,30 \%$ de cobre metático a cada 14 dias.

É importante o resultado verificado no sistema convencional, no qual pulverizações a cada sete dias com $0,15 \%$ de cobre metálico ou a cada 14 dias com $0,30 \%$ impediram totalmente o surgimento de lesões de cancro cítrico nos enxertos, apesar do ataque severo que havia acontecido nos porta-enxertos.

Por sua vez, os dados da tabela 4 indicam que a presença de lesões de cancro cítrico foi grande no sistema de cultivo orgânico. Isto, entretanto, não deve ser interpretado como menor eficácia da calda bordalesa, pois, segundo THEISEN (2004), a calda bordalesa possui ação de controle semelhante à do oxicloreto de cobre. O fato também não deve ser atribuído a diferenças no crescimento das plantas, o qual, pelo contrário, foi maior no sistema convencional. No sistema orgânico, ocorreu um ataque intenso e constante de larva-minadora, que diminuiu o crescimento dos enxertos, tornando as folhas mais suscetíveis à penetração do agente causal do cancro

Tabela 4 - Índices de ataque de cancro cítrico em folhas de enxertos de laranjeira "Valência” enxertadas sobre porta-enxertos de Poncirus trifoliata Raf. que haviam sido inoculados com Xanthomonas citri pv. citri e depois pulverizados com duas concentrações e três freqüências de aplicação de bactericidas cúpricos, em dois sistemas de cultivo (orgânico e convencional). Centro de Formação da Emater/RS, no Município de Montenegro - RS, 2003.

\begin{tabular}{|c|c|c|c|c|c|c|}
\hline \multirow[b]{2}{*}{ Tratamentos } & \multicolumn{3}{|c|}{ Cultivo orgânico } & \multicolumn{3}{|c|}{ Cultivo convencional } \\
\hline & $\begin{array}{c}\text { Nov. de } \\
2002\end{array}$ & $\begin{array}{c}\text { Março de } \\
2003\end{array}$ & $\begin{array}{c}\text { Maio de } \\
2003\end{array}$ & $\begin{array}{c}\text { Nov. de } \\
2002\end{array}$ & $\begin{array}{c}\text { Março de } \\
2003\end{array}$ & $\begin{array}{c}\text { Maio de } \\
2003\end{array}$ \\
\hline Testemunha, sem pulveriz. cúprica & $0 \mathrm{a}$ & $56 a^{1}$ & $15 \mathrm{ab}^{1}$ & $0 \mathrm{a}$ & $8 a^{1}$ & $2 a^{1}$ \\
\hline 0,15 \% de Cu metálico a cada 7 dias & 0a & $22 \mathrm{~b}$ & $9 \mathrm{~b}$ & $0 \mathrm{a}$ & $0 \mathrm{~b}$ & $0 \mathrm{~b}$ \\
\hline 0,15 \% de Cu metálico a cada 14 dias & $0 \mathrm{a}$ & 29ab & $16 a b$ & $0 \mathrm{a}$ & $1 \mathrm{ab}$ & $1 \mathrm{ab}$ \\
\hline 0,15 \% de Cu metálico a cada 21 dias & $0 \mathrm{a}$ & $49 a$ & 29a & $0 a$ & $1 \mathrm{ab}$ & $1 \mathrm{ab}$ \\
\hline 0,30 \% de Cu metálico a cada 7 dias & $0 \mathrm{a}$ & $21 \mathrm{~b}$ & $10 \mathrm{~b}$ & $0 \mathrm{a}$ & $0 \mathrm{~b}$ & $0 \mathrm{~b}$ \\
\hline 0,30 \% de Cu metálico a cada 14 dias & $0 \mathrm{a}$ & $25 \mathrm{~b}$ & $10 \mathrm{~b}$ & $0 \mathrm{a}$ & $0 \mathrm{~b}$ & $0 \mathrm{~b}$ \\
\hline 0,30 \% de Cu metálico a cada 21 dias & 0a & $23 \mathrm{~b}$ & $17 \mathrm{ab}$ & 0a & $1 \mathrm{ab}$ & $0 \mathrm{~b}$ \\
\hline Médias dos tratamentos & $0 \mathrm{C}^{2}$ & $32,14 \mathrm{~A}$ & $15,14 \mathrm{~B}$ & $0 \mathrm{C}$ & $1,57 \mathrm{~A}$ & $0,57 \mathrm{~B}$ \\
\hline
\end{tabular}

${ }^{1}$ Médias seguidas por letras minúsculas distintas na coluna diferem entre si pelo teste de Duncan ao nível de significância de 0,05.

${ }^{2}$ Médias seguidas por letras maiúsculas distintas na linha diferem entre si pelo teste de Duncan ao nível de significância de 0,05 . 
cítrico. Assim sendo, para melhorar o controle do cancro cítrico, com pulverizações de calda bordalesa, em sistemas orgânicos de cultivo, devem ser desenvolvidas medidas de controle da larva-minadora mais eficazes do que o uso de Bacillus thurringensis. CONCLUSÕES

A eficiência de pulverizações cúpricas no controle do cancro cítrico aumenta com a diminuição do intervalo de aplicação e com o aumento da concentração de cobre metálico na solução. A melhor resposta é obtida com a concentração de $0,3 \%$, em intervalos de 14 dias, nas fases de brotação das plantas. Os sistemas convencional e orgânico proporcionam desenvolvimento semelhante aos porta-enxertos, porém $\mathrm{o}$ ataque mais intenso da larva-minadora diminui o desenvolvimento de enxertos no sistema de cultivo orgânico.

\section{AGRADECIMENTOS}

Os autores agradecem ao Programa RS-Rural do Estado do Rio Grande do Sul pelo apoio financeiro e à Coordenação de Aperfeiçoamento de Pessoal de Nível Superior (Capes) e ao Conselho Nacional de Desenvolvimento Científico e Tecnológico $(\mathrm{CNPq})$ pela concessão de bolsas de estudos.

\section{REFERÊNCIAS}

AMORIN, L. et al. Epidemiologia do cancro cítrico. Summa Phytopathologica, Jaboticabal, v.27, n.1, p.151-156, 2001.

CABRITA, J.R.M. et al. Medidas de prevenção e combate do cancro cítrico. Revista Laranja, Cordeirópolis, v.2, p.201211, 1981.

CANTEROS, B.I. Manejo de enfermedades en Citrus: cancrosis, moteado negro (black spot) y caída anormal de frutos. In: CICLO DE PALESTRAS SOBRE CITRICULTURA DO RS, 12., 2005, Faxinal do Soturno. Anais... Porto Alegre,: UFRGS, FEPAGRO e EMATER/RS, 2005. p.113-128.
FAO, Food and Agriculture Organization of the United Nations. Faostat agriculture data, agricultural production, crops primary. Capturado em 15 julho 2005. On line. Disponível na Internet: http://www.fao.org.

GOTTWALD, T.R. et al. Citrus canker: the pathogen and its impact. Plant Management Network. Capturado em 08 nov. 2002. On line. Disponível na Internet: http: // www.apsnet.org.

IBGE, Instituto Brasileiro de Geografia e Estatística. Levantamento Sistemático da Produção Agrícola. Capturado em 18 julho 2005. On line. Disponível na Internet: http://www.sidra.ibge.gov.br.

LEITE JUNIOR, R.P. et al. Controle integrado de cancro cítrico - efeito da resistência genética e da aplicação de bactericidas. Fitopatologia Brasileira, Brasília, v.12, n.3, p.259-263, 1987.

LEITE JUNIOR, R.P. et al. Susceptibilidade do limão Siciliano (Citrus limon), enxertado sobre diferentes porta-enxertos, ao cancro cítrico causado por Xanthomonas campestris pv. citri. Fitopatologia Brasileira, Brasília, v.13, n.4, p.353-358, 1988.

LEITE JUNIOR, R.P. Cancro cítrico no Estado do Paraná aos 40 anos. Summa Phytopathologica, Jaboticabal, v.23, n.1, p.91-92, 1997.

MACIEL, J.L.N. Resistência ao cobre e perfil de restrição de ADN plasmidial de Xanthomonas campestris pv. citri. 1994. 69f. Dissertação (Mestrado em Fitotecnia) - Programa de Pós-Graduação em Fitotecnia, Universidade Federal do Rio Grande do Sul.

MAVRODIEVA, V. et al. Improved sampling methods for real time polymerase diagnosis of citrus canker from field samples. Phytopathology, Beltsville, v.94, n.1, p.61-68, 2004.

THEISEN, S. Incidência de cancro cítrico (Xanthomonas citri pv citri) em pomar de laranjeiras 'Valência' sob concentrações e freqüências de pulverizações cúpricas. 2004. 63f. Dissertação (Mestrado em Fitotecnia) - Programa de Pós-graduação em Fitotecnia, Universidade Federal do Rio Grande do Sul. 